\title{
Concept mapping impact on self-efficacy for enhancing students' motivation and performance in biology
}

\author{
Michael Adiyiah ${ }^{1}$, Dieudonne Mutangana ${ }^{2}$ and Yaw Ameyaw ${ }^{3}$
}

\begin{abstract}
The impact of students' self-efficacy beliefs about their academic performance and motivation in all stages of their academic endeavour has been a major concern to many researchers. It contributes greatly to the overall total development and success of the student even at their progression to the next level in their educational development. The purpose of this quasi-experimental study was to investigate the effect of using concept mapping strategy as an intervention strategy on the development of students' self-efficacy beliefs about their motivation and performance in biology. One hundred and twenty students from two different Senior High Schools in Ashanti Region of Ghana were involved in the experiment. Two instruments, namely students' self-efficacy and motivation questionnaire as well as students' achievement test were used in the data collection and the results were analyzed using Pearson product-moment correlation, oneway ANOVA and multiple regression statistics. The findings of the study indicated that effective regular use of concept mapping strategy has a strong and positive influence on students' self-efficacy beliefs about their development which enhances their motivation to learn and performance in biology.
\end{abstract}

Keywords self-efficacy beliefs; academic performance; intrinsic motivation; extrinsic motivation

\section{Introduction}

The educational significance of self-efficacy and motivation on students' performance in learning and teaching has been a major area of prime interest that inspire most scholars and research practitioners alike, but the strategic paradigm is how can it be enhance and develop using an innovative and interactive strategy. Many studies have supported and provided sufficient empirical data in support of its effectiveness on students' academic output and their success at school as well. The extent to which students believe that they can exile to enhance their' learning outcome, in educational context for enhancing their performance in science education programmes depends on their self-efficacy belief and motivation held towards that particular instructional subject. Research studies have emphasized that students' self-efficacy development has been allied with planned effort and perseverance in managing and handling challenging tasks (Solmaz, 2016) in learning and teaching situations. The concept of self- efficacy beliefs and academic performance, as well as, participation in science, and coping with innovative methods in learning and teaching as interventional strategies to deal with learning challenges are positive step for improving

\footnotetext{
${ }^{1}$ Michael Adiyiah. University of Rwanda-African Centre of Excellent for Innovative Learning of Mathematics and Science. Email: michaeladiyiah@gmail.com, +250780598976, +233543588813.

2 Dieudonne Mutangana, University of Rwanda, Department of Biology. College of Science and Technology, mature02@gmail.com, +250788358282

${ }^{3}$ Yaw Ameyaw, University of Education, Winneba-Ghana. Department of Biology Education. syameyaw@yahoo.com, +233249025713

Open Access article distributed under the terms of the Creative Commons Attributions License [CC BY-NC-ND 4.0] http://creativecommons.org/licenses/by-nc-nd/4.0. DOI: https://dx.doi.org/10.4314/ajesms.v16i1.6
} 
Concept mapping impact on self-efficacy for enhancing students' motivation and performance in biology

M. Adiyiah, D. Mutangana, \& Y. Ameyaw science education. Although many related studies (e.g., Ashton and Webb 1986, Solmaz, 2016) have shown that students' self-efficacy has influence on students' interest and performance, unfortunately, most of these studies have not been able to discuss effectively the relationship between students' self-efficacy on their motivation and academic performance.

In addition, not many studies have investigated the effect of self-efficacy across groups of students in different schools and settings especially how to enhance the development of less efficacious and poorly motivated students using appropriate intervention. The aim of this study was to investigate if any significant change exists in the relationship between students' self-efficacy, academic performance, and motivation development after concept mapping exposure, and finally, to determine which component of the students' motivation influences their performances in biology most.

\section{Self-efficacy effect on motivation and academic performance}

Educational research studies on how the concept of self-efficacy have influenced and enhanced students' performance and success in learning and teaching can largely been traced and abstracted within Bandura's (1994; 2002) concept of self-efficacy theories. Students' self- efficacy has been explained as the extent to which the learners are confident enough with concepts understanding and practices to enhance their learning effectively (Bandura, 1994). According to Bandura, individuals' behavior is inspired by the collaboration of two kinds of expectations: self-efficacy belief and outcome expectancy which explains how peoples' assessment of their proficiency to undertake and complete successfully a specific task in a particular context, and the former deals with judgments about the likelihood significance that performance might be achieve. It has been realized that highly effective student tends to be more prepared, display efficient skills of trying to make meaning of all instructions, explaining and discussing, questioning and providing appropriate feedback to instructor with special challenges as well as maintaining tireless on appropriate tasks. Whereas less effective students, display a very protective and more of negative attitude to classroom management process, spend significantly more hours on particular project as opposed to timeliness completion of tasks and managing challenges related to instruction, feel frustrated and threatened always, and experience difficulty in maintaining and controlling his conduct on task accomplishment.

In addition to relevant concepts like self-efficacy and attitudes effect on students' performance in learning, research has indicated that motivation need to be promoted among learners especially towards learning of sciences if effective performance is the target of our most discussions. According to research by Pintrich and Schunk (2003), the concept of academic motivation is explained as "a process for goaldirected activity that is instigated and sustained" (p. 5). It is therefore explained that students are motivated to learn and is achieve when they believe that their effort expenditure on their learning activities in an instructional process are satisfactory. In context, this means that the students' belief about their academic capabilities play an important role in their motivation to achieve success in learning and motivation is seen as fundamental aspect of learning. Thus, to be motivated means to be moved beyond assume effort to do extraordinary. As explained in related studies, components of motivation can be excitement, interest and enthusiasm towards 
learning (Goldberg \& Cornell, 1998). It is argued by the self-determination theory that motivation is of type base on the purpose or reason made for any action. The most distinction made is the difference between intrinsic and extrinsic motivation according to the self-determination theory, concept of extrinsic motivation is the undertaking of any responsibility that the individual find it interesting and enjoyable (Goldberg \& Cornell 1998). Intrinsically, individual demonstrate efficient effort and highly organized to learn from their inaccuracy. They are quick to learn and integrate their existing knowledge from their previous experience to form deeper understanding with new concept of existing knowledge. From related literature, intrinsic motivation generates deep understanding whiles extrinsic motivation provides surface and low impact learning and that intrinsically motivated persons are able to concentrate better and longer on academic task. They develop the best of ability to use series of integrated strategies to face challenges in their learning. Moreover, it is discussed that students who are intrinsically motivated are better in exercising self-regulation and work hard with concentration for achieving the goal of mastery in learning. In addition to intrinsic and extrinsic motivational dimensions explained above, Deci and Ryan (2000) added amotivation dimension, which is explained as the individual concerned unwilling to perform a particular learning task. It shows how learners administer their in-built dissatisfaction towards events. Notwithstanding, the relevant literature did not include any studies which were specifically based on academic motivation for learning biology rather studies were mainly about students' general academic motivation. This study will therefore contribute to the field of biology education in this respect. It is aimed to analyze the relationship between high school biology students' self-motivational development, for promoting self-directed learning skills for enhancing academic performance in learning of biology.

\section{Concept mapping in biology instruction}

The concept and practice of assisting students to represent their cognitive understanding in concept maps (Novak \& Gowin, 1984) has been very useful for enhancing performance in sciences especially biology education. This learning technique has been supported in many biological research studies in education (Ajaja, 2011 \& Ameyaw, 2012). The process of constructing concept maps assist students to understand concepts relationships between different ideas. Concepts of biology require understanding of abstraction on concrete, semiconcrete or abstract experience of students. Representation and organization of these biological ideas or relations are important, and most students have challenges in developing relational and conceptual understanding. Engaging in meaningful learning requires the use of relevant prior knowledge application, use of meaningful material, and the choice of the students in question. Concept maps help students to relate newly learned ideas. It also helps student's matches' new ideas to old concepts (Ajaja, 2011 \& Ameyaw, 2012).

The application of concept mapping has its theoretical foundations from the principle of Piaget and Ausubel. Newly learned concepts and knowledge cause the disequilibrium with old concepts, then students reach a cognitive equilibrium by assimilation or accommodation. Reaching cognitive equilibrium means that students formed the new cognitive or conceptual organizations. Concept maps guide students to organize their conceptual schema and represent their cognitive ideas in a peculiar way (Roth \& Roychoudhury, 1992, p. 357). This organization gives instructors and students the opportunity to assess progress in instructional delivery and learning respectively. Misconceptions and alternate concepts may be revealed during concept mapping activities and due remediation effected. 
Concept mapping impact on self-efficacy for enhancing students' motivation and performance in biology

M. Adiyiah, D. Mutangana, \& Y. Ameyaw Concept maps are dynamic and students add new component based on their experiences. Since biological ideas and concepts consist of complicated and complex forms of relations especially in photosynthesis, the students gain more insight, they develop complicated and integrated concept maps. Concept maps were constructed mostly at the end of an instructional period and/or subject, but it is most appropriately to be ongoing to reorganize students' ideas and make connections between the smaller elemental components within the subject instructional process. It is very effective in promoting students understanding and retention of concepts taught, especially during the analysis of students' achievement as well as for positive development of students' affective domain towards science instruction. The teacher assist students to note and understand the main concept to be learn, use interactive constructivist approach to guide learners in critical thinking to discover related concepts and sub-concepts connected to the major topic under discussion. Presentation of drawn maps using nodes and links with the discovered concepts in a hierarchical pattern and relationship for criticism and justification until final submission portraying meaningful conceptual understanding.

Although many studies reviewed indicate concept mapping as effective for promoting students' performance and results, little is said about its usage for developing students' selfefficacy and motivation for enhancing academic performance especially among low and less motivated achievers in biology. This provides a good justification and a gap in literature for more studies in the areas. To effectively measure this aim, the study addressed the following research questions: 1 . What is the impact of concept mapping intervention on students' selfefficacy and motivation development for enhancing their performance in photosynthesis? 2. What is the difference in photosynthesis performance among the students after the concept mapping intervention? 3. What is the influence of the various developed motivational dimensions on students' performance in photosynthesis after the intervention?

\section{Methodology}

One hundred and twenty (120) students in different classes of two mixed Senior High Schools of less efficacious, motivated and low achieving classes contributed to this study. They were guided on how to fill the self-efficacy and motivation questionnaire items and were divided into three ability groups for administration of the intervention using the concept mapping for teaching photosynthesis. The students' grades were used as academic performance scores for the analysis. The self- efficacy and motivation questionnaire consisted of 17 and 28 items respectively. The motivation items was adapted from Solmaz (2016) and modified. The researcher developed students' academic self-efficacy scale based on bandura's four sources of self-efficacy within the context of academic performance in biology for use in this study.

All the questionnaires used a 5-point Likert scale (ranging from 1 (strongly disagree) to 5 (strongly agree), to rank the students' level of self-efficacy and motivation development. They were piloted to check its reliability and validity to avoid any element of ambiguity and other related challenges in the main study implementation.

Using Cronbach alpha, the reliability estimates of the two questionnaires were determined to be 0.76 and 0.75 , which were reasonably acceptable index of reliability coefficient. The students' motivation consists of four main parts: the first, second and third parts focused on students' positive responses, intrinsic (item 1-8), extrinsic-career (item 9-13), and the third part extrinsic- social (14-19), the fourth part seeks out information on negativities of students towards biology (20-28). In order to examine the validity of the researchers selfdeveloped self-efficacy items, experts were made to scrutinize it, and some were modified 
and others deleted based on comments from them. Factor analysis was performed to identify how the questionnaires functioned, if they actual load into the four components of each was higher than 0.30 communality. The overall factorability of the data was done prior to factor analysis, and the result indicated that factor analysis was appropriate, and could result in reliable information during their administration.

The process of this study was carried out in May 2019 using pre-intervention, the intervention and post-intervention stages of data collection activities. Careful explanation was made to the biology students on how they were expected to complete the questionnaires items, only assign codes and their class identifications, and were expected on the questionnaires for the purpose of matching their performance scores accordingly, and assurance of confidentiality was given.

Thereafter, the pre-intervention motivation and self-efficacy questionnaires were distributed among them to complete. After they have completed filling the questionnaires, the data were collected, and the students were divided into two groups, based on their level of selfefficacy. The poor achieving students of low self-efficacy and poorly motivated in preintervention stage were taught the concept of photosynthesis for a period of four weeks using closeness indices as regular assessment tool. After the tutorial classes, the students were made to fill out the students' post-intervention self-efficacy and motivation questionnaires, and their achievement scores in photosynthesis form were collected from their class teachers, and the data were analyzed using SPSS version 21 software.

\section{Experimental results and findings}

The study discussed three research questions: the first research question examines the relationship between students' self-efficacy on students' motivation and academic performance. Pearson product-moment correlation was performed on students' selfefficacy, students' performance and motivation responses. It was again performed on the students' self- efficacy and each dimension of the students' motivation responses. Table 1 indicates the result of correlation coefficient on students' responses:

Table 1 The pre-intervention relationship between students' self-efficacy and motivation and performance

\begin{tabular}{lllcc}
\hline Self-efficacy1 & & \multicolumn{3}{c}{ Performance } \\
& & \multicolumn{1}{c}{1} & \multicolumn{1}{c}{ Motivation 1 } \\
\hline \multirow{2}{*}{ Self-efficacy1 } & Pearson correlation & 1 & .134 & -.029 \\
& Sig. (2-tailed) & & .143 & .754 \\
& $\mathrm{~N}$ & 120 & 120 & 120 \\
\hline \multirow{3}{*}{ Performance } & Pearson correlation & 1 & $.997^{* *}$ & $.993^{* *}$ \\
& Sig. (2-tailed) & & .000 & .000 \\
& $\mathrm{~N}$ & 120 & 120 & 120 \\
\hline
\end{tabular}

**. Correlation is significant at the 0.01 level (2-tailed).

As shown in Table 1, a significantly positive correlation coefficient exists between developed self-efficacy and students' motivation and performance. Therefore, it can be concluded that the higher the students' self-efficacy, the higher the students' motivation as well as their performance. Table 2, also indicates a significant relationship between 
Concept mapping impact on self-efficacy for enhancing students' motivation and performance in biology

M. Adiyiah, D. Mutangana, \& Y. Ameyaw students' self-efficacy and different dimensions of students' motivation (i.e., extrinsiccareer, extrinsic- social, intrinsic motivation and amotivation) in this study.

Table 2 The relationship between student self-efficacy and different dimensions of the students' motivation

\begin{tabular}{lrrrrr}
\hline & Performance & M-society & M-career & Amotivation & Intrinsic \\
\hline $\begin{array}{l}\text { Pearson correlation } \\
\text { Self-efficacy }\end{array}$ & $.997^{* *}$ & $.985^{* *}$ & $.997^{* *}$ & $.294^{* *}$ & $.995^{* *}$ \\
$\quad$ Sig. (2-tailed) & .000 & .000 & .000 & .001 & .000 \\
$\mathrm{~N}$ & 120 & 120 & 120 & 120 & 120 \\
\hline
\end{tabular}

As the table above indicates, there is a high significant positive correlation between students' self-efficacy and the different dimensions of students' motivation, however, for the correlation between students' self-efficacy and students' amotivation dimension, the result seems interesting: the more the self-efficacy of the students, the less the amotivation of the students' predicted.

The second objective of this study was to again examine if there exist any significant difference between students' biology photosynthesis performance based on their developed level of self- efficacy. An inferential statistical analysis was performed using one-way Anova to critically examine if there is any significant differences in students' biology performance in different ability groups that contributed to this study, so that meaningful comparison can be made based on their developed level of self-efficacy. The results indicated no significant differences among the groups as seen in the Anova results (i.e. Table 3 ) despite their slightly mean differences realized among them as $(83.33,82.78$, and 82.89).

Table 3 One-way Anova results on students' biology performance between the groups

\begin{tabular}{llllll}
\hline & Sum of squares & Df & $\begin{array}{l}\text { Mean } \\
\text { square }\end{array}$ & F & Sig. \\
\hline Between groups & 7.422 & 2 & 3.711 & .147 & .863 \\
Within groups & 2952.444 & 117 & 25.235 & & \\
Total & 2959.867 & 119 & & & \\
\hline
\end{tabular}

The research question three also investigated the influence of the various motivational dimensions on academic performance in photosynthesis, the result with multiple regression analysis is shown in Tables 4, 5 and 6. 
African Journal of Educational Studies in Mathematics and Sciences Vol. 16, No. 1. 2020

Table 4 Descriptive analysis and inter-correlation between variables

\begin{tabular}{lllllllll}
\hline Variable & N & Mean & SD & $\begin{array}{l}\text { Perfor- } \\
\text { mance }\end{array}$ & $\begin{array}{l}\text { M- } \\
\text { Society }\end{array}$ & $\begin{array}{l}\text { M- } \\
\text { Career }\end{array}$ & Intrinsic & $\begin{array}{l}\text { A-moti- } \\
\text { vation }\end{array}$ \\
\hline Performance & 120 & 83.03 & 4.987 & 1.000 & & & & \\
M-society & 120 & 26.17 & 4.925 & .975 & 1.000 & & & \\
M-Career & 120 & 31.07 & 4.946 & .997 & .987 & 1.000 & & \\
Intrinsic & 120 & 37.95 & 7.647 & .998 & 971 & .995 & 1.000 & \\
Amotivation & 120 & 15.10 & 1.647 & .294 & .291 & .296 & .283 & 1.000 \\
\hline
\end{tabular}

Table 5 Analysis of variance of joint significant effect of independent variables

\begin{tabular}{llllll}
\hline Model & Sum of squares & Df & $\begin{array}{l}\text { Mean } \\
\text { square }\end{array}$ & F & Sig. \\
\hline Regression & 2956.736 & 4 & 739.184 & 27151.440 & $.000 \mathrm{~b}$ \\
Residual & 3.131 & 115 & .027 & & \\
Total & 2959.867 & 119 & & & \\
\hline
\end{tabular}

Multiple R (adjusted) $=.999$

Multiple $\mathrm{R}^{2}$ (adjusted) $=.999$

Standard error of estimate $=.165$

Table 6 Effect and significance of the independent variables

\begin{tabular}{|c|c|c|c|c|c|c|}
\hline \multirow{2}{*}{\multicolumn{2}{|c|}{ Model }} & \multicolumn{2}{|c|}{$\begin{array}{l}\text { Unstandardized } \\
\text { coefficients }\end{array}$} & \multicolumn{2}{|c|}{$\begin{array}{l}\text { Standardized } \\
\text { coefficients }\end{array}$} & \multirow[b]{2}{*}{ Sig. } \\
\hline & & B & Std. Error & Beta & $\mathrm{T}$ & \\
\hline & (constant) & 52.769 & .330 & & 159.733 & .000 \\
\hline & M-society & -.220 & .026 & -.217 & -8.412 & .000 \\
\hline & M-career & .861 & .060 & .854 & 14.311 & .000 \\
\hline & Amotivation & .008 & .010 & .003 & .849 & .398 \\
\hline & Intrinsic & .241 & .026 & .359 & 9.112 & .000 \\
\hline
\end{tabular}

Table 4 indicates that biology performance using photosynthesis, and it significantly correlated with (1) M-social ( $\mathrm{r}=\mathrm{a} .975 ; \mathrm{p}<0.05)$, (a2) M-career $(\mathrm{r}=.997 ; \mathrm{p}<.05)$ and (3) Intrinsic $(\mathrm{r}=998 ; \mathrm{p}<.05)$ and (4) Amotivation $(\mathrm{r}=.294 ; \mathrm{p}<.05)$. There were also significant correlations among the various motivational dimensions. Table 5 shows that all the motivational dimensions have a joint significant effect on photosynthesis performance in biology except Amotivation. This means that the capacity of the three dimensions to predict photosynthesis performance could not have happened by chance. The coefficient of determination (R2) of 0.999 implied that almost $100 \%$ of the variation in biology performance is been explained by the M-society, M- career and Intrinsic dimensions. Table 6 also shows how each of the dimensions positively affect biology academic performance and in terms of magnitude of effect, M-career has the most significant effect (beta $=854$ : 
Concept mapping impact on self-efficacy for enhancing students' motivation and performance in biology

M. Adiyiah, D. Mutangana, \& Y. Ameyaw $\mathrm{t}=14.311 ; \mathrm{p}<.05$ ), follow by Intrinsic (beta=359: $\mathrm{t}=9.112 ; \mathrm{p}<.05$ ) and then M-social (beta $=217 ; \mathrm{t}=8,412 ; \mathrm{p}<.05)$.

\section{Conclusions}

The research study examined the difference and relationship between student self-efficacy development impact on students' motivation and academic performance. Notwithstanding, it also investigated the effect of students' self-efficacy on the students' performance in biology, and finally, what influences do the academic motivation dimensions have on students' performance in biology using photosynthesis. The Pearson product-moment correlation coefficient performed among students self-efficacy, on academic performance and students' motivation, and the four different dimensions of students' motivation (i.e. Mcareer, M-social, intrinsic and amotivation), in order to examine whether there is any significant relationship between students self-efficacy and students' motivation, and also the different dimensions of the students' motivation questionnaire or not.

The analyses showed that there is a reasonably high positive correlation between students developed self-efficacy and students' motivation and their academic performance. Thus, it can be discussed that there is existence of a student self-efficacy positively influence on students' motivation as a result of the treatment (concept mapping) effect on the students self-efficacy development, which was not the case as seen in the pre-intervention relationship of poor negative correlation influence between the student self-efficacy on students motivation and academic performance, (Table 3). It also indicated a positive correlation between students' self-efficacy and all the dimensions of the students' motivation that is M-career, M-social, intrinsic and amotivation. The degrees of correlation were $.997, .985, .995$ and .294 for $\mathrm{M}$ - career, M-social, intrinsic and amotivation respectively. But the results only showed minimum correlation between student selfefficacy and students' amotivation which buttress the findings of Solmaz, (2016)).

In Ghanaian context, low amotivation among students could be explained as getting a better grade in biology as an opportunity for student in getting an admission into tertiary or university and not for the purpose of job acquisition and hence justified. According to finding in this study, students with a higher level of self-efficacy are able to change their attitude toward learning biology, and consider biology as a favourite subject for developing their life. The impact of students' developed self-efficacy on their biology performance was discussed in research question two. The result of one-way ANOVA indicated that the differences in the students' biology performance in different ability groups are not significant and this shows a significant improvement among the groups, especially among the low achievers based on their post-intervention biology performance. The result of this findings shows that the students' in all the three different ability groups had achieved higher level of self-efficacy after concept mapping exposure, and got better scores than their preintervention scores as a result of treatment effect. In other words, it can be inferred that the higher the level of student self-efficacy, the higher the students' performance. The results of this study support the findings of the previous researches suggesting a significant correlation between students' self-efficacy and increased students' academic performance, by influencing teachers' instructional practices, enthusiasm, commitment, and teaching behavior (Tschannen-moran \& hoy, 2001; Tournaki \& Podell, 2005; Wolters \& Daughtery, 2007). The results are also in line with bandura's observation (1994) that students who have a strong sense of efficacy about their capabilities can motivate themselves and improve their cognitive development. However, an important review of the study shows that amotivation 
had a weakly relationship with the self- efficacy, and all the other components; the motivation, academic performance and for that matter the use of the concept mapping intervention. This is due to the fact that students who are unenthusiastic and less motivated shows poor interest in Biology, and hence, have low self- efficacy and poor internal motivation. They cannot cope with any innovative instructional strategy at a significant level, and do not think that learning biology will contribute to their selection of a future profession in life. These findings are in consistence with similar review Wolters and Daugherty (2007), which discusses that amotivation weakly and negatively correlated with other variables of motivation.

The current study adds to our understanding of the self-efficacy and motivation beliefs of students, and provides support for the use of these students' self-efficacy scale outside subject related fields and cultural settings. Thus, we can confidently hypothesize that students' self-efficacy can influence their academic motivation and performance in different settings, and thus, it is not subject and context-bound. It is also important that in any educational environment, as well as, schools' management principles to provide maximum opportunity in order to enhance students' self-efficacy, and consequently, improve students' motivation and performance (Tschannen-moran et al., 2007). The results of this study indicated that there is a strong positive influence of students' motivation on students' academic performance in biology using the concept of photosynthesis. However, much other valuable information remains to be learned about the role of students' self-efficacy in learning and teaching especially sciences, mathematics, and technology education (STEM). The ideas and concepts below are necessary for further research based on this study:

1. There should be further studies to examine the effect of teacher self- efficacy on students' selection of sciences or biology programme.

2. Further research study should be done to examine if students' self-efficacy beliefs can be moderated or change as a result of specific school administrators' principle and practices.

3. An investigation should be conducted to find out if the level of students' selfefficacy and motivation development differs among various categories of teachers' instructional strategies in schools.

\section{References}

Ajaja, O. P. (2011). Concept mapping as a study skill: Effects on Students Achievement in Biology; International Journal Education Science, 3(1): 49-57.

Ameyaw, Y. (2012). Closeness index an assessment tool for student's performance of cell theory. International Journal of Science and Nature. Vol.3 (3)2012; $532-537$

Ameyaw Y, \& Okyer, M. (2018). The efficacy of some teaching and learning instructions that enhance students' performance in Excretion. Ann Resear, 1(5): 555571

Ahmad, M. \& Marzieh, P. T. (2012). The Impact of Teacher Self-efficacy on the Students' Motivation and Achievement. Theory and Practice in Language Studies, Vol. 2, No. 3, pp. 483-491,

Ashton, P. T., \& Webb, R. B. (1986). Making a difference: Teachers' sense of efficacy and student achievement. New York: Longman 
Concept mapping impact on self-efficacy for enhancing students' motivation and performance in biology

M. Adiyiah, D. Mutangana, \& Y. Ameyaw

Bandura, A. (2002). Social cognitive theory in cultural context. Journal of Applied Psychology: An international Review, 51, 269-290

Deci, E. L., \& Ryan, R. M. (1985). Intrinsic motivation and self-determination in human behaviour. New York: Plenum Press. http://dx.doi.org/10.1007/978-14899-2271-7

Goldberg, M. D. \& Cornell, D. G. (1998). The influence of motivation and selfconcept on academic achievement in second and third-grade students. Journal for the Education of the Gifted, 21(2), 179-205.

Goldsmith, T. E., Johnson, P. J., \& Acton, W. H. (1991). Assessing structural knowledge.

Moran, M. \& Hoy, A. (2001). Teacher efficacy: capturing an elusive construct. Teaching and Teacher Education, 17, 783-805.

Novak, J.D., \& Gowin, R. (1984). Learning how to learn (3rd Edition). New York: Cambridge University press.

Pintrich, P. R. \& Schunk, D. H. (2002), Motivation in education: Theory, research and applications (2nd Ed). Columbus, $\mathrm{OH}$ : Merrill-Prentice Hall

Podell, D. \& Soodak, L. (1993). Teacher efficacy and bias in special education referrals. Journal of Educational Research, 86, 247-253.

Roth, W. R. \& Roychoudhury, A. (1992). The social construction of scientific concepts or concept map as conscription device and tool for social thinking in high school science. Science Education, 76(5), 531-557.

Solmaz, A.(2016) An Analysis of the Relationship between High School Students' Self- efficacy, Metacognitive Strategy Use and their Academic Motivation for Learn Biology, Journal of Education and Training Studies, Vol. 4, No. 2; pg.5

Tournaki, N., \& Podell, D. (2005). The impact of student characteristics and teacher efficacy on teachers' predictions of student success. Teaching and Teacher Education 21, 299- 314

Tschannen-Moran, M. \& Woolfolk Hoy, A. \& Hoy, W. K. (1998) Teacher efficacy: Its meaning and measure, Review of Educational Research, 68, 202-248.

Tschannen-Moran, M., \& Hoy, A. W. (2001). Teacher efficacy: Capturing an elusive construct. Teaching and Teacher Education, 17(7), 783805.

Wolters, C. A., \& Daugherty, S. G. (2007). Goal structures and teachers' sense of efficacy: their relation and association to teaching experience and academic level. Journal of Educational Psychology, 99, 181-193. 
African Journal of Educational Studies in Mathematics and Sciences Vol. 16, No. 1. 2020

Open Access article distributed under the terms of the Creative Commons Attributions License [CC BY-NC-ND 4.0] http://creativecommons.org/licenses/by-nc-nd/4.0. DOI: https://dx.doi.org/10.4314/ajesms.v16i1.6 
African Journal of Educational Studies in Mathematics and Sciences Vol. 16, No. 1. 2020

Open Access article distributed under the terms of the Creative Commons Attributions License [CC BY-NC-ND 4.0] http://creativecommons.org/licenses/by-nc-nd/4.0. DOI: https://dx.doi.org/10.4314/ajesms.v16i1.6 